\title{
On English Conversations from the Perspective of Cooperative Principle and Politeness Principle
}

\author{
Zujun Chen \\ Xi'an Peihua University, Xi'an, Shaanxi 710000, China \\ 37092309@qq.com
}

\begin{abstract}
Through the analysis of specific conversations, we can see that not all conversations are conducted according to the cooperation principle. There are also cases of deliberate violation of these norms in conversation. In many cases, it violates this principle and produces conversational implicature, which is largely due to politeness.
\end{abstract}

Keywords: cooperative principle; politeness principle; conversational implicature.

\section{Introduction}

In daily communication, most of the conversations are conducted by means of oral communication between people. Conversation is one that involves two or more people to complete together, including talk, discussion, interview and other specific forms. People talk, especially in conversation, always to express a certain meaning or to communicate for the purpose, generally follow certain guidelines. However, there are often situations in conversation where someone has to or even intentionally violates these norms. [1]

There are generally two kinds of meaning in conversation. One is the literal meaning expressed by the words and sentences spoken by the speaker, and the other is the implied meaning expressed by the speaker. [2] Among them, the real meaning of the implied speaker is called conversational implicature. [3]

Therefore, the understanding of conversation should rely on certain pragmatic reasoning ability, that is, the common sense and common background knowledge of the speaker. An important premise here is to follow the CP (cooperative principle) proposed by Grice in the late 1960s. Although the principle of cooperation is an important principle of conversation, it is not the only one. Sometimes one of the parties may intentionally violate the principle of cooperation and express their ideas and communicate in an implicit and indirect way. In order to make up for the deficiency of the cooperative principle, Leech, a British linguist, proposed the politeness principle PP (politeness principle), which enables the conversational implicature to be better interpreted.

\section{Concept of Cooperation Principle and Politeness Principle}

\subsection{Grice's CP (Cooperative Principle) has the Following Four Guidelines.}

(1). Quantity maximum. The level of detail is required to achieve the current purpose of the conversation. You can't make what you say more detailed than what you ask for.

(2). Quality maximum. Don't say what you know is false. Don't say anything without enough evidence.

(3). Relationship Maxim. Speak with relevance.

(4). Manner Maxim. Avoid ambiguity, avoid ambiguity be brief and be orderly.

\subsection{Leech Summarized the Politeness Principle into the Following Six Principles:}

(1). Tact Maxim: make others suffer the least; make others benefit the most.

(2). Generosity: make oneself benefit the least; make oneself damage the least.

(3). Approval maximum: try to minimize the derogation to others; try to exaggerate the praise to others.

(4). Modesty maxim: try to narrow the praise to oneself; try to exaggerate the derogation to oneself. 
(5). Agreement maxim: try to narrow the differences between oneself and others; try to exaggerate the agreement between oneself and others.

(6). Sympathy maxim: try to reduce your dislike of others; try to exaggerate your sympathy for others.

\section{Use of Cooperative Principle and Politeness Principle through Specific Conversation}

Theoretically speaking, the principle of cooperation should be obeyed by every speaker. However, in real communication, there are often various phenomena that violate the principle, resulting in conversational implicature or illocutionary meaning. Here is a brief analysis of each situation.

\subsection{Follow the Principle of Cooperation in Conversation, which Produces a Situation of Literal Meaning}

Example 1 A: How many sisters do you have?

B: Three.

In example 1, the answer of speaker B is just in line with the requirement of the quantity principle of cooperation principle.

Example 2 A: Do you think Jack is a suitable person to do this job?

B: Yes, absolutely.

B's answer is to express that what he wants to say is true, if there is enough evidence, so it completely conforms to the quality criteria. At this time, the meaning of conversation is literal.

Example 3 A: How did you like the collection?

B: I think it wonderful.

This dialogue is appropriate and relevant, and conforms to the relationship principle in the principle of cooperation.

Example 4 A: A: Mary's skirt is beautiful, isn't it?

B: Yes, I think so.

This session is short, orderly, and in line with the manner principle.

\subsection{Violate the Principle of Cooperation, Resulting in Conversational Implicature}

Although it can't be said that people's violation of conversational norms results in conversational implicature because of politeness, in many cases, people do it out of politeness. [2]

Example $5 \mathrm{~A}$ : Can you have dinner with us this evening

B: I'd love to, but I'm afraid I can't.

According to the requirements of the cooperation principle, B should answer "yes, I can." or "no, I can't." but B intentionally violates the principle of quantity and manner in the cooperation principle and expresses the content that should be directly expressed in a euphemistic way. This is not easy to explain the principle of cooperation. At this time, the politeness principle put forward by the British linguist Leech gives us a reasonable explanation. In verbal communication, the communicators all want to be respected by the other party, so in order to respect the other party, the speaker needs to adapt to the context to take some appropriate communication strategies to show politeness. So there occur some different situations, such as the straight talk, the short talk and the long talk, and the truth hypothesis. In many cases, the reason why the communicator intentionally violates the principle of cooperation is to maintain the dignity of both sides of the communication, form a friendly communication atmosphere, and establish a friendly interpersonal relationship. So politeness principle is a useful supplement to cooperation principle.

Leech believes that only through the politeness principle can the cooperative principle fully explain the problems of implicature and indirect speech act. Another example is shown here:

Example 6 A: We'll all miss bill and Agatha, won't we?

B: Well, we'll all miss Bill. 
According to the principle of cooperation, B violates the principle of quantity, mentioning only bill instead of Agatha. It is obviously intentional for B to do so. He has a special conversational meaning. For some reason, he may be dissatisfied with Agatha, but it is inconvenient for him to speak directly because of the situation, which makes him violate the principle of cooperation. Obviously, it's the politeness principle that works. In this case, the speaker follows the principle of approval in politeness principle, saying something that is not polite to the hearer or the third party, or omitting it or saying it politely or indirectly.

Example 7 A: So what do you think of my new haircut?

B: Did you see the Blue Jays game last night? [4]

This is an example of violating the relevant maxim in the cooperation principle. B's answer is not related to A's question, and B can't lack relevant information, because A's question involves B's subjective feeling, and B refuses to cooperate with A's topic, so we can see that the meaning of conversation is: "I'm not interested in your new haircut. Practically, your haircut is not good." B shifts the topic in time to avoid the unhappiness brought to A by talking about this topic, thus maintaining the strategic principle of politeness principle.

Example 8. (It's late. The host talks to Tracy who lives in the suburb.)

Hostess: You look tired, Tracy. George can drive you back.

Tracy: Oh, thank you for your party. I've got go.

In this case, the guest's response violated the relationship principle in the cooperation principle, did not directly respond whether he was very tired, and did not express any opinions on letting George drive her home. The hostess's words are from the perspective of sympathy for the guests, concern for her health and road safety. Its real conversational meaning is to express the "should go" instruction to the guests. The euphemistic expression makes the guests accept it happily and achieves the successful communicative purpose. It also takes into account the principle of politeness without directly saying "it's too late, you should go." It can be seen that the use of politeness principle in communication can better promote the smooth progress of dialogue and achieve the expected purpose.

Example 7 A: What do you think of my dress?

$\mathrm{B}$ : Well, the color is beautiful.

According to the requirements of cooperation principle, B should answer "it's beautiful." or "it's not beautiful at all." But B's answer does not evaluate the whole skirt, but only comments on the color of the skirt. He does not include the level of detail required to make what he said achieve the purpose of conversation, and it is easy to have ambiguity. It violates the maxims of quantity and manner in cooperation principle. B is very clever in his answer. He may not like A's skirt very much, but he didn't say "I don't like it at all." Instead, he followed the praise principle in the politeness principle, tried to reduce the derogation to others, praised the beautiful color of the skirt, so as to save face for $\mathrm{A}$ and avoid conflict.

Example 10 A: How do you like my painting?

B: I don't have eye for beauty, I'm afraid.

B's answer violates the relationship principle in the cooperation principle. He doesn't make any comments on A's painting, but just shows that he doesn't have any vision for beauty. But B, out of the humility principle of politeness principle, tried to exaggerate his derogation, deliberately violated the principle of cooperation, which indirectly expressed the meaning of "I don't like it at all", and successfully completed the communication. It can be seen from this that sometimes kind modesty can also produce illocutionary meaning, so as to express the negative meaning that the speaker does not want to express directly.

Example $11 \mathrm{~A}$ and B have a dialogue after watching the movie "perfect nine beauties":

A: I like the film very much.

B: Well, I like it to some degree.

B's answer uses "to some degree", which is a bit vague. Its purpose is that B doesn't want to sweep A's interest and maintain A's face, so that the topic can go on. In daily life, for a certain benefit or a certain purpose, or to achieve a certain effect, or for both parties to work together without any conflict, people will naturally use the principle of approval. 
Example 12 A: I think the film "the hours" was good tonight.

B: Yes, quite good, but some parts are rather boring, don't you think so ?

Obviously, B didn't like the movie, but he first affirmed the judgment of the other party, then changed his mood, expressed his different views in the form of antonym questions and in the tone of discussion. B follows the principle of approval, exaggerates the agreement between others and him as much as possible, narrows the differences between others and him, and expresses politely.

As can be seen from examples 11 and 12, people like to get along with and work with people who have the same views. However, human personality is so different that different views and opinions will inevitably arise on the same thing, so contradictions and differences are inevitable. In order to keep communication from being affected, one of the most effective ways is to seek common ground while reserving differences, that is, to be good at finding common ground from differences, to minimize the differences with others, to maximize the same opinions with others, and to maintain the politeness principle, so as to promote the success of communication.

Example $13 \mathrm{~A}$ : English is a very diverse language to learn.

$\mathrm{B}$ : True, but the grammar is quite easy.

$\mathrm{B}$, by agreeing with A's point of view and then explaining his own view on the easy learning of grammar in English, agrees with all but negates the part, so as not to arouse the opposition of the other party. When people criticize others, they affirm its advantages first, then point out its shortcomings, make it easy to accept, and reduce its aversion to such criticism. B's answer conforms to the principle of sympathy in politeness.

Of course, there are also violations of the principle of cooperation rather than politeness considered. Generally, those situations are in special context, so we will not make specific analysis here.

\section{The Relationship between Politeness Principle and Cooperation Principle}

Theoretically speaking, the principle of cooperation should be obeyed by every speaker. However, in real communication, there are often various phenomena that violate the principle, resulting in conversational implicature.

Grice's cooperative principle and Leech's politeness principle are two important theories in pragmatics. Cooperative principle plays a role in adjusting the content of the speaker's speech in conversation, which enables the speaker to communicate under the assumption that the other party is willing to cooperate. However, politeness principle has a higher regulatory role, which maintains the equal status of both sides of the conversation and the friendly relationship between them. Only under this premise can people communicate. In order to maintain the principle of politeness, people can even sacrifice the principle of cooperation. [2]

Therefore, in the analysis of daily conversation, we should not only consider the principle of cooperation, but also consider the influence of politeness principle on conversation, so as to better understand the meaning of conversation and achieve the purpose of correct communication.

\section{Acknowledgements}

This paper is the phased achievement of the university-level project PHKT19057of Xi'an Peihua University - A Research on the Cognitive Tendency and Strategic Mode of WeChat Circle of Friends Advertisement for College Students Based on Grice's Cooperative Principle.

\section{References}

[1]. Shenyang. Fifteen Lectures on Linguistics [C]. Beijing: Peking University Press, 2005, 11.

[2]. He Zhaoxiong. A Brief Introduction to Pragmatics [M]. Shanghai: Shanghai Foreign Language Education Press, 2000, 3. 
[3]. Dai Weidong, Xu dingfang, Zhou Xuelin, Chen Xiafang. Introduction to Modern English Linguistics [M]. Shanghai Foreign Language Education Press, 1998, 8.

[4]. Kingwell, Mark. Is It Rational to Be Polite? [J] The Journal of Philosophy 90 (8), 1993. 